\title{
0 adeus dos fãs: John Updike e o imaginário esportivo do beisebol
}

\section{The farewell of the fans: John Updike and the baseball imaginary}

\author{
Guilherme Fragosso do Prado \\ Discente do curso de Comunicação Social - Habilitação em Jornalismo da \\ Universidade Federal de Uberlândia.
}

\section{Guilherme Fragosso do Prado}

Professor Adjunto, classe C1, da Universidade Federal de Uberlândia, onde atua no Curso de Jornalismo e no Programa de Pós-Graduação - Mestrado Profissional em Tecnologias, Comunicação e Educação da Faculdade de Educação (FACED/ UFU) desde 2013. Diretor da FACED/UFU pelo mandato 2017/2021. Doutor em Meios e Processos Audiovisuais pela Escola de Comunicações e Artes da Universidade de São Paulo (ECA/USP - 2013). Possui também o mestrado em Ciências da Comunicação (2010) e graduação em Comunicação Social: Habilitação em Jornalismo (2008), todos também pela ECA/USP.

\section{RESUMO}

O beisebol, em pouco tempo, se tornou o esporte mais popular dos Estados Unidos. Tornou-se, também, uma inspiração para o jornalismo norteamericano que se utilizava de elementos literários para narrar as jogadas e os mitos dos jogadores, elevando-os a condição de heróis. Nos anos 1960, o novo jornalismo, mesmo despretensioso, esse estilo permitiu ao jornalista utilizar-se de sua subjetividade para contar os fatos. John Updike, representante do novo jornalismo e autor da crônica trabalhada nesta pesquisa, encontraram no beisebol uma de suas inspirações. Para análise, foi utilizado o conceito de Narratologia e o modelo atuacional de Algirdas J. Greimas e a concepção de ficção e realidade da Rosana Soares, Marcelo Bulhões e Jean-Paul Sartre, buscando a constatação do engendramento entre ficção e realidade nas crônicas de beisebol no novo jornalismo. Palavras-chave: Beisebol; Novo Jornalismo; Ficção; Realidade.

\section{ABSTRACT}

Baseball, soon became the most popular sport in the United States. It became also an inspiration for American journalism which used literary elements to narrate the plays and myths of the players, bringing them the status of heroes. In the 1960s, New journalism, even unassuming, allowed the journalist used his subjectivity to tell the facts. John Updike, representative of the new journalism and author worked on this research, found in baseball one of his inspirations. For analysis, we used the concept of Narratology and the actantial model Algirdas J. Greimas and the conception of fiction and reality from Rosana Soares, Marcelo Bulhões and Jean-Paul Sartre, seeking a finding of engendering between fiction and reality in baseball chronic the new journalism. Keywords: Baseball; New Journalism; Fiction; Reality 
A história do beisebol começa oficialmente em 1839, na cidade de Cooperstown, nos Estados Unidos. Foi apenas em 1845, porém, que a primeira equipe oficial do beisebol surgiu, denominada de Knickerbocker Base Ball Club de Nova Iorque. Fundado por Alexander Cartwright, o Knickerbocker protagonizou ainda outro dado histórico: foi derrotado, por 23 a 1, na primeira partida que se tem registro nos Estados Unidos, em 1846 (VIEIRA; FREITAS, 2009).

Ao longo das décadas seguintes, o prestígio do esporte foi aumentando nos Estados Unidos e os times profissionais começaram a aparecer. Em 1903, uma organização profissional norte-americana de beisebol, a Major League Baseball (ou Liga Principal de Beisebol, em português) uniu as principais ligas do país, a Nacional e a Americana, e criou um campeonato nacional (JAMES, 2003).

No início do século XX, a imprensa norte-americana começa a fazer a cobertura de esportes, como o beisebol, a partir de crônicas e contos, influenciados pela literatura. O nome do primeiro time de beisebol, o Knickerbocker, por exemplo, foi inspirado em um personagem da literatura. Diedrich Knickerbocker foi o narrador do livro "Knickerbocker's History of New York, Complete”, de Washington Irving, publicado inicialmente em 1809. O sobrenome do narrador se tornou, tempos depois, um sinônimo, um apelido para cidadão nova-iorquino, mais especificamente para os residentes de Manhattan.

Desse modo, uma mística literária se iniciou em volta do beisebol, em que ídolos eram retratados como heróis, jogadas eram eternizadas e que a ficção estava entrelaçada com a realidade. "Beisebol, o mais amado dos esportes norte-americanos, é também o mais poético” (DAWIDOFF, 2002, s. p.).

Mas como definir uma crônica do beisebol como jornalismo se há elementos subjetivos e ficcionais? Na década de 60 do século XX nos Estados Unidos, a objetividade do texto jornalístico começou a ser questionada, em consonância com o espírito transgressor da época. Era o início, mesmo que sem pretensão, do New Journalism. O Novo Jornalismo, influenciado pela literatura, rompe com a imprensa tradicionalmente objetiva e permite o jornalista se aproximar do fato, participando ou não do texto, e utilizar-se de sua subjetividade, como caracterização dos personagens e detalhamento do espaço.

O beisebol se tornou uma inspiração para esse novo estilo de jornalismo. Os contos conseguem descrever os fatos de uma partida e, ao mesmo tempo, misturar elementos ficcionais, subjetivos. Entre os autores que escreveram sobre o esporte está John Updike, que contribuiu com crônicas e 
novelas para a revista norte-americana The New Yorker.

A partir dos conceitos da Narratologia do francês Algirdas J. Greimas e da concepção de ficção e realidade da Rosana Soares, Marcelo Bulhões e Jean-Paul Sartre, foi possível responder a questão: como se dá o engendramento do imaginário narrativo nas crônicas de beisebol do Novo Jornalismo e como essa união constrói a cultura literária desse esporte? O foco aqui é em restrito em John Updike e seu texto Hub Fans Bid Kid Adieu.

\section{Narratologia e o Modelo Atuacional}

Para se entender a Narratologia e o Modelo Atuacional (ou denominado de Actancial) de Algirdas Julius Greimas, utilizados como suporte para alcançar os objetivos desta pesquisa, é preciso conhecer as características principais do Estruturalismo, que teve como expoentes conceituais o linguista Ferdinand Saussure e o antropólogo Claude Lévi-Strauss. Para os estruturalistas, a realidade, em todos os seus níveis, poderiam ser explicados pelas estruturas, ou seja

[...] parte do pressuposto de que cada sistema é um jogo de oposições, presenças e ausências, constituindo uma estrutura, onde o todo e as partes são interdependentes, de tal forma que as modificações que ocorre num dos elementos constituintes implicam na modificação de cada um dos outros e do próprio conjunto (GIL, 2014, p. 19).

Assim, um fato observado para o estruturalismo não pode ser isolado, já que ele é um elemento que está em interdependência com outros, tendo seu sentido alterado de acordo a posição que ocupa em relação aos demais num modelo. E, para que esse modelo científico possa ser denominado de "estrutura", deverá satisfazer quatro condições:

Em primeiro lugar, uma estrutura apresenta um caráter de sistema. Consiste em elementos tais que uma modificação de qualquer um deles acarreta uma modificação de todos os demais. Em segundo lugar, todos os modelos pertencem a um grupo de transformações, cada uma das quais correspondendo a um modelo da mesma família, de modo que o conjunto dessas transformações constitui um grupo de modelos. Em terceiro lugar, as propriedades indicadas acima permitem prever de que modo reagirá o modelo em caso de modificação de um de seus elementos. Finalmente, o modelo deve ser de tal modo construído que seu funcionamento possa dar conta de todos os fatos observados (LÈVI-STRAUSS, 1967, p. 302). 
Desta forma, temos que os modelos propostos por Greimas (tanto o Atuacional quanto o Transformacional) conseguem satisfazer essas condições e se encaixarem nas características principais do Estruturalismo. Esses dois modelos, a partir de uma análise de qualquer narrativa, poderiam responder dois questionamentos:

[...] a) quais são as relações recíprocas e o modo de existência em comum dos atuantes de um micro-universo? b) qual é o sentido, muito em geral, da atividade que atribuímos aos atuantes? Em que consiste esta 'atividade', e se ela é transformadora, qual é o quadro estrutural dessas transformações? (GREIMAS, 1973, p. 226).

Para exemplificar como os dois modelos supracitados se distinguem, Greimas (1973) descreve que um mitólogo, ao analisar uma população divina inteira, percorre dois caminhos. No primeiro, Deus entra como atuante, a partir de suas atividades e funções como divindade. Já no segundo, o mesmo Deus é descrito a partir de suas qualificações, de seus atributos. Desta forma, há duas definições possíveis para essa mesma divindade:

[...] a primeira, que faz parte do princípio de que um deus é reconhecido pelo que faz, mas que considerando mítica sua atividade, inscreve-o como um dos atuantes de um universo ideológico; a segunda que o situa como um dos atuantes com o auxílio dos quais contextualiza uma axiologia coletiva. (GREIMAS, 1973, p. 225).

A segunda definição se encaixa no Modelo Transformacional, enquanto que a primeira pode ser inserida no Modelo Atuacional, analisando as relações dos atuantes e suas funções dentro de um espaço, como em narrativas. Essas narrativas, porém, são permanentes, pois mesmo que as ações e os atores dentro dela mudem, a distribuição dos papéis dentro dessa estória continuará a mesma (GREIMAS, 1973).

Essa é a mesma concepção que Vladmir Propp. A partir dos contos populares russos, Propp estudou que a concepção dos atuantes, ou dramatis personae como ele mesmo define, é funcional e que as personagens são definidas de acordo com as "esferas de ação" que participam na narrativa. (GREIMAS, 1973). Um atuante então seria uma função que um ator, ou chamado de personagem, pode possuir dentro do conto. Essa função, porém, pode se alterar dependendo da mensagem que o ator precisa passar. 
Vladimir Propp define um inventário definitivo de sete atuantes que compõem a narrativa de um conto popular russo: (1) o vilão; (2) o destinador; (3) o adjuvante; (4) a pessoa procurada; (5) o proclamador (aquele que chama o herói para a ação); (6) o herói e (7) o falso herói (um enganador). (GREIMAS, 1973).

Saindo dos contos russos, a reflexão sobre os atuantes também chega às peças teatrais, apresentada pelo francês Étienne Souriau. "O interesse do pensamento de Souriau consiste no fato de ter ele mostrado que a interpretação atuacional podia se aplicar a um tipo de narrativas - as obras teatrais - bem diferente do conto popular e que seus resultados podiam ser comparáveis aos primeiros" (GREIMAS, 1973).

Apesar das semelhanças com Propp, Souriau limita a quantidade de atuantes nas peças teatrais para seis, e não sete como nos contos russos. São eles:

Leão, a Força temática orientada; Sol, o Representante do Bem desejado, do valor orientado; Terra, o Obtenedor virtual desse Bem (aquele para o qual trabalha o Leão); Marte, o Oponente; Balança, o Árbitro, atribuidor do Bem; Lua, o Auxílio, reduplicação de uma das forças precedentes (GREIMAS, 1973, p. 230).

Para Greimas (1973), tanto Propp quanto Souriau contribuíram para a definição desse número limite de atuantes o bastante para dar conta de um microuniverso, mas insuficientes se pensarmos em outras narrativas além dos contos russos e das peças teatrais e sem analisar as possíveis relações entre os próprios atuantes. Assim, a partir dessas análises anteriores, Greimas categoriza um novo inventário de atuantes. Ele também classifica os personagens das narrativas de acordo com o que fazem, pela participação em uma esfera de ações e não segundo o que são.

Na categoria sintática de Greimas, o "herói versus a pessoa procurada", de Vladimir Propp, e "força temática orientada versus Representante do Bem desejado, do valor orientado", de Étienne Souriau, se tornam "Sujeito versus Objeto". O “Árbitro versus Obtenedor" e "destinador versus proclamador" são equivalentes a "Destinador versus Destinatário", em Greimas. Por fim, os últimos atuantes, "O Auxílio versus O Oponente" e "o adjuvante versus o vilão", são adaptados para "Adjuvante versus Oponente” (GREIMAS, 1973, p. 231-234).

Deste modo, com as adaptações realizadas dos dois outros autores, 
Algirdas Greimas sintetiza e cria um modelo atuacional que "está inteiramente fundado sobre o objeto do desejo do sujeito e situado, como objeto de comunicação, entre o destinador e o destinatário, sendo o desejo do sujeito, por seu lado, modulado em projeções do adjuvante e do oponente" (GREIMAS, 1973, p. 235-236).

Figura 1: Modelo Atuacional Greimasiano

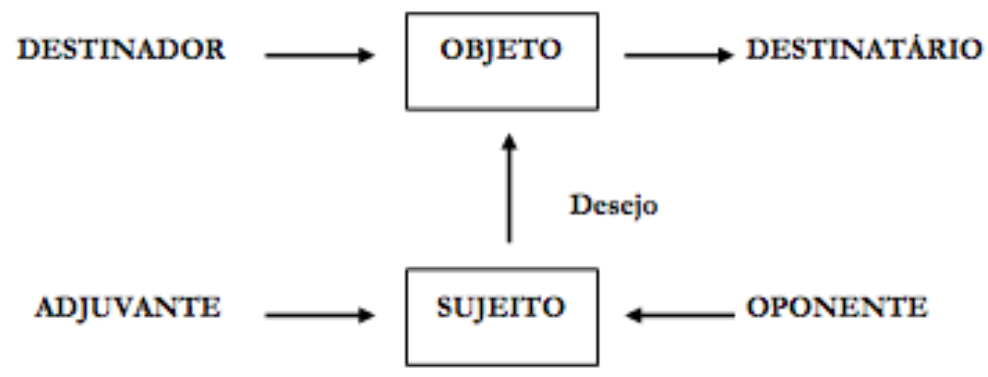

O desejo, neste caso, é a força que guiará o sujeito em busca do objeto pretendido. Em algumas narrativas, porém, esse desejo "é susceptível de uma transformação negativa, no sentido de passar a ser uma obsessão ou uma fobia" (RECTOR, 1978, p. 99). O par "adjuvante versus oponente" corresponde à modalidade do poder, já que o adjuvante consiste em auxiliar o sujeito-herói no sentido do desejo ou facilitar sua comunicação, enquanto que o oponente tenta criar obstáculos para a realização desse desejo ou prejudicar a busca pelo objeto (GREIMAS, 1973).

\section{Ficção e Realidade nas Narrativas}

Uma narrativa, então, pode ser definida como um código que

[...] se ordena segundo as regras de três níveis: o da fábula, o das personagens e o da maneira de contar. Portanto, ancorado nesse molde, tenho para mim, na esteira dos estudos de narratologia, que narração constitui a instância em que o narrador, enquanto sujeito manipulador, têm mais possibilidades de desenvolver sua imaginação criativa. Disso se tem prova quando o leitor centra seu interesse não exclusivamente nas peripécias ou no desempenho dos atores, mas também na maneira de arranjar esses elementos [...] (PEÑUELA CAÑIZAL, 2007, p. 4). 
Apesar da frequente associação com os elementos da ficção, como a subjetividade da história contada, a narrativa também pode estar ligada a fatos verídicos e não somente fictícios. Assim, “[...] a narrativa não é privilégio do relato ficcional, constituindo também o relato factual" (SOARES, 2010, p. $59)$.

Um texto fictício, por exemplo, assim como os produzidos pelo romancismo estadunidense nas décadas de 30 a 50 no século XX, não está impossibilitado de expor profundas verdades humanas, assim como um texto realista não está isento de expressar a mais intensa subjetividade do autor (TELLES, 2010). Para Bulhões (2007), pensar a literatura, como esses romances norte-americanos, apenas como um processo de fabulação e de utopia, que não contém aproximações com a realidade é um pensamento errôneo.

[...] é preciso dizer que a ficcionalidade não pode ser exclusivamente associada à ideia do absurdo ou do improvável imaginativo, nem ser compreendida como uma instância estranha e incomunicável como o real empírico. Ela trama relações complexas com a chamada factualidade (BULHÕES, 2007, p. 20).

No caso do novo jornalismo, por exemplo, os discursos também não são totalmente ficcionais ou reais, eles se misturam em alguns pontos. De acordo com Soares (2010), as narrativas são compostas por dois mundos opostos, porém não contraditórios: o mundo imaginário e o mundo histórico. Os dois mundos contém realidades e ficções. Os fatos retratados na crônica deste trabalho, por exemplo, são reais e estão no mundo histórico, mas possui vestígios ficcionais, que são objetos irreais, pertencentes ao mundo imaginário.

Os objetos irreais são as imagens elaboradas na mente a partir do real (SARTRE, 1996). Quando o indivíduo imagina algo, ele não está imaginando a "coisa em si", o objeto real, mas sim, o irreal. O objeto irreal é a "coisa aproximada", tirada da sua realidade e colocada em função da imaginação da pessoa (SARTRE, 1996). Esta aproximação ocorre através do ato da imaginação, que "é um ato mágico. É um encantamento destinado a fazer aparecer o objeto no qual pensamos, a coisa que desejamos, de modo que dela possamos tomar posse" (SARTRE, 1996, p. 165).

Dessa forma, podemos afirmar que o factual e o ficcional - como pode ser percebido não só no jornalismo, mas também no cinema, na teledramaturgia ou nos reality shows - são campos que têm borrado, cada vez mais, os limites entre suas fronteiras, afastando-se da distinção comumente a eles atribuída entre relatos verdadeiros ou falsos, 
reais ou imaginários. (SOARES, 2010, p. 59-60).

Assim, a partir das estruturas do modelo atuacional e dos conceitos abordados neste tópico, foi possível nos aprofundarmos nas narrativas e alcançar o objetivo principal deste projeto: analisar a união da ficção e da realidade nas crônicas sobre beisebol

\section{Hub Fans Bid Kid Adieu}

Hub Fans Bid Kid Adieu (ou Fãs da Base Dão Adeus ao Garoto, na tradução portuguesa) foi escrita originalmente em 1960 pelo jornalista John Updike e publicada no dia 22 de outubro do mesmo ano, pela revista norte-americana The New Yorker (UPDIKE, 1960). Em 2010, a crônica foi relançada em formato de livro, de 64 páginas, com uma introdução feita pelo próprio Updike, em homenagem ao aniversário de 50 anos da aposentadoria de Ted Williams, sendo esta uma das últimas obras realizadas antes de falecer ainda em 2009 (UPDIKE, 2010).

Faz-se necessário, primeiramente, explicar o título da crônica. Os torcedores de beisebol são conhecidos como Fãs da Base (Hub Fans), por conta das bases do campo, e Garoto (Kid) era um dos apelidos do jogador do Boston Red Sox, Ted Williams, por causa do seu corpo esguio. O texto, realizado a partir da percepção de John Updike, relata o dia em que Williams rebate pela última vez como jogador profissional de beisebol, no Fenway Park, em Boston.

Eu, e outros 10.453, tínhamos aparecido principalmente porque aquele era o último jogo em casa do Boston Red Sox na temporada, e, portanto, a última vez em toda a eternidade que aquele seu habitual jardineiro esquerdo, conhecido pelas manchetes como TED, GAROTO, SPLINTER, THUMPER, TW e, o mais sentimentalista, MISTER MARAVILHOSO, jogaria em Boston (UPDIKE, 1960 apud DAWIDOFF, 2002, p. 302, tradução nossa).

Ted Williams é considerado um dos melhores jogadores de todos os tempos no bastão, mas também um dos mais polêmicos. "Ele fazia gestos obscenos para os fãs, guardava rancor por muitas décadas contra repórteres específicos, às vezes não tratava sua família bem, às vezes não se esforçava ou nem mesmo fingia qualquer tipo de esforço em campo ou nas bases" (JAMES, 2003, p. 652, tradução nossa). 
John Updike escreveu, de maneira poética, uma crônica que demonstrasse o espírito polêmico e perseverante de Ted Williams. Em seu último jogo, por exemplo, o jogador de Boston conseguiu acertar um solo home run e ajudar na vitória dos Red Sox contra o Baltimore Orioles, por 5 a 4, mesmo aos 42 anos de idade.

A bola subiu numa linha diagonal para o vasto volume de ar sobre o campo central. Do meu ângulo, atrás da terceira base, a bola parecia menos um objeto em voo do que a ponta de uma imponente estrutura imóvel, como a Torre Eiffel ou a ponte Tappan Zee. Estava nos livros enquanto ainda estava no céu (UPDIKE, 1960 apud DAWIDOFF, 2002, p. 316, tradução nossa).

No meio da narrativa, enquanto não relata a partida de despedida, John Updike se recorda de que, quando conheceu Ted Williams pela primeira vez, ainda era um garoto e morava no estado da Pensilvânia. "Eu me lembro de ouvir pelo rádio o Jogo das Estrelas de 1946, no qual Williams acertou dois singles e dois home runs" (UPDIKE, 1960 apud DAWIDOFF, 2002, p. 306, tradução nossa).

Aplicando-se a metodologia do modelo atuacional de Greimas na crônica Hub Fans Bid Kid Adieu, para entender o papel de cada atuante e compreender a narrativa como um todo, obtemos a seguinte figura:

Figura 9: Modelo Atuacional Hub Fans Bid Kid Adieu

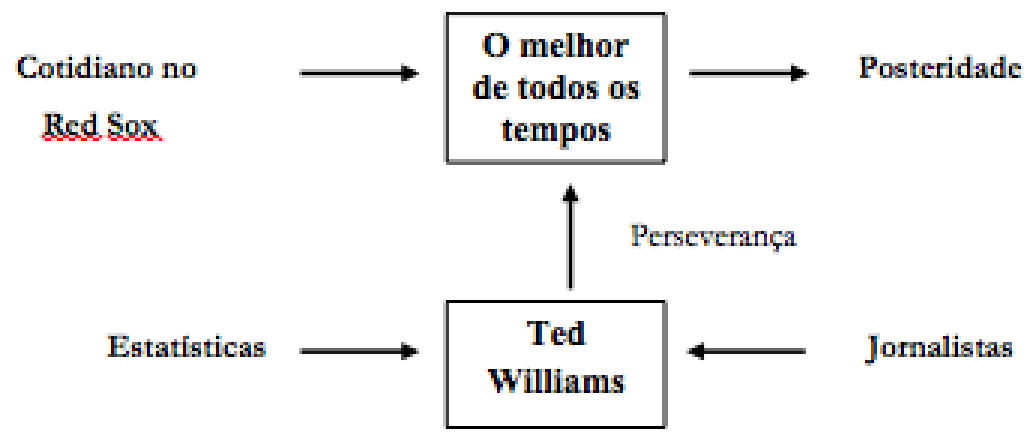

Fonte: elaboração do autor a partir do modelo de Greimas (1973)

A partir do modelo apresentado, podemos, então, definir o jogador do Boston Red Sox, Ted Williams, como o sujeito da crônica, já que esta se ba- 
seia na última vez em que ele joga beisebol pela MLB e na história do atleta e de seus feitos ao longo da carreira. "Em duas décadas desde que Williams veio para Boston, o status dele mudou imperceptivelmente de um prodígio malcriado para um monumento da cidade"1 (UPDIKE, 1960 apud DAWIDOFF, 2002, p. 306, tradução nossa).

No modelo atuacional, o sujeito, orientado por um desejo, quer alcançar o objeto. No caso da crônica Hub Fans Bid Kid Adieu o objeto de Ted Williams era se tornar uma lenda no beisebol, pois tudo que ele queria era que as pessoas o reconhecesse como o melhor rebatedor que já existiu. Para Updike (1960 apud DAWIDOFF 2002), Williams, mesmo sendo imortalizado e sua camisa aposentada, não chegou ao seu objeto, mas pode ser considerado o melhor rebatedor da sua época.

O desejo, que guia o sujeito até o objeto, neste caso, é a perseverança. Ted Williams não desistiu de seu sonho de se tornar o melhor rebatedor e sempre retorna para o jogo. Em 1957, embora tenha ficado doente e considerado já velho para o esporte, com 39 anos, Williams conseguiu rebater quatro home runs consecutivos, 39 ao total na temporada inteira, e alcançar a média de 38,8\%, a maior desde a sua própria marca de 40,6\%, ainda em 1942.

Mesmo após ter se passado três anos como piloto da Marinha norte-americana durante a Segunda Guerra Mundial, Williams retornou para o Boston Red Sox e continuou jogando beisebol em busca do objeto. E é a perseverança que o motiva em 1959. "Em 1959, pareceu que tudo acabou. O dinossauro [Williams] batia por volta de $20 \%$ no pântano na primeira metade da temporada, e foi até para o banco ('um descanso', o técnico Mike Higgins diplomaticamente disse)"2 (UPDIKE, 1960 apud DAWIDOFF, 2002, p. 309, tradução nossa). Mesmo forçado a se aposentar depois de uma temporada ruim, Williams não desistiu e voltou mais uma vez.

Os jornalistas se opõem à realização do objeto e do desejo do sujeito, já que Ted Williams possuía um mau convívio com repórteres "Foi uma teoria cara - que provavelmente lhe custou, entre outras evidências de boa vontade, dois prêmios de Jogador Mais Valioso, que é votado por repórteres - mas ele teve que aguentar"33 (UPDIKE, 1960 apud DAWIDOFF, 2002, p. 304, tradução nossa).

1 Original: "In the two decades since Williams had come to Boston, his status had imperceptibly shifted from that of a naughty prodigy to that of a municipal monument"

2 Original: "In 1959, it seemed all over. The dinosaur thrashed around in the 200 swamp for the first half of the season, and was even benched ('rested', Manager Mike Higgins tactfully said.)".

3 Original: It has been a costly theory - it has probably cost him, among other evidences of good will, two Most Valuable Player awards, which are voted by reporters-but he has held to it". 
Teoria essa que Dawidoff (2002) também acredita, pois em 1947 e 1957, Joe DiMaggio e Mickey Mantle ganharam o prêmio de Jogador Mais Valioso, respectivamente, mesmo com temporadas e números inferiores à Ted Williams, que ficou apenas em posições intermediárias. Essa parte evidencia ainda mais o oponente, já que os jornalistas tentam impedir o sujeito de alcançar o objeto, o melhor rebatedor de todos os tempos, não votando nele para o prêmio de melhor jogador.

Em outra parte da crônica, antes da partida de despedida, Williams ao realizar seu discurso para o estádio, expõe todo o rancor que possui pelos jornalistas, dizendo que jamais esqueceria as coisas terríveis que eles, os "maestros do teclado", escreviam nos jornais sobre o atleta de Boston.

Para ajudar o sujeito na busca pelo objeto, temos o adjuvante que, na crônica Hub Fans Bid Kid Adieu, são as estatísticas. São os números de Ted Williams que impulsionam o debate se ele é o maior rebatedor que já viveu ou não. O autor, John Updike, cria uma dicotomia entre as estatísticas positivas e as negativas, comparando-as. Negativamente, temos: "na lista dos recordes de rebatidas na Major League, nenhuma é encabeçada por Williams. Ele é o segundo em walks, terceiro em home runs, [...] décimo quarto em doubles e trigésimo em acertos”4 (UPDIKE, 1960 apud DAWIDOFF, 2002, p. 304, tradução nossa).

Outro ponto negativo apontado pelo autor está nos jogos cruciais, quando Williams pouco rendeu e ficou abaixo da média habitual, demonstrando não ser um jogador de decisão. Updike, entretanto, desconstrói essas estatísticas desfavoráveis ao citar que Boston Red Sox era a pior equipe nas últimas 27 temporadas e que, mesmo considerado bom no papel, não conseguia ser na prática, explicando, assim, a falta de conquistas coletivas.

Mas são as estatísticas positivas que auxiliam Ted Williams no percurso em busca do objeto e que desconsideram as marcas negativas, pois as positivas são mais importantes no contexto da narrativa, já que há mais uma valorização dos feitos de Williams que desmerecimento de seus feitos. "A partir das estatísticas que estão nos livros, um bom caso pode ser feito em uma combinação da força e média onde Williams é o primeiro; ninguém mais ranqueia tão alto em ambas as categorias" ${ }^{\prime 5}$ (UPDIKE, 1960 apud DAWIDOFF, 2002, p. 311, tradução nossa).

$4 \quad$ Original: "in the list of major-league batting records, not one is held by Williams. He is second in walks drawn, third in home runs, [...] fourteenth in doubles, and thirtieth in hits".

5 Original: "From the statistics that are on the books, a good case can be made that in the combination of power and average Williams is first; nobody else ranks so high in both categories". 
Além disso, para um jogador de 42 anos, suas estatísticas, mesmo no final da carreira e considerado acabado pelo baixo rendimento em 1959, ainda eram impressionantes. A única temporada que pode se comparar com a de Ted Williams, com a mesma idade, é a de Ty $\mathrm{Cobb}^{6}$, que conseguiu uma média de 32,3\% e apenas um home run em 1928, enquanto o jogador do Boston Red Sox, apesar da média inferior de 31,6\%, teve 39 home runs (UPDIKE, 1960 apud DAWIDOFF, 2002).

No atuante do destinador, podemos defini-lo como o cotidiano que Ted Williams possuía no Red Sox antes de se aposentar. Williams jogou somente pela equipe de Boston sua carreira toda e, apesar das polêmicas, era lá que ele queria alcançar o objeto, citando que os anos na cidade foram as melhores coisas na vida dele.

O caso entre Boston e Ted Williams não foi um mero romance de verão; foi um casamento, composto por brigas, decepções mútuas, e, perto do fim, um acúmulo amadurecido de memórias compartilhadas. Esse caso se divide em três partes, que podem ser chamadas de Juventude, Maturidade e Velhice; ou Tese, Antítese e Síntese; ou Jason, Aquiles e Nestor ${ }^{7}$ (UPDIKE, 1960 apud DAWIDOFF, 2002, p. 302, tradução nossa).

O sujeito, auxiliado pelo adjuvante, as estatísticas, e guiado pela perseverança, busca ser o melhor rebatedor a partir do início da ação dada pelo destinador, o Red Sox. Na outra parte do modelo atuacional, definimos que o destinatário é a posteridade, os acontecimentos posteriores à aposentadoria de Ted Williams.

No final da entrada, Higgins retirou Williams de sua posição no campo esquerdo, então instantaneamente o substituiu por Carrol Hardy, então nós tivemos uma última e extensa olhada em Williams enquanto ele saía de lá e então voltava, com seu uniforme sacudindo, seus olhos fixos no chão ${ }^{8}$ (UPDIKE, 1960 apud DAWIDOFF, 2002, p. 317, tradução nossa).

6 Ty Cobb, jardineiro central, jogou pela equipe do Detroit Tigers de 1905 a 1926 e, depois, pelo time dos Philadelphia Athletics, de 1926 a 1928 (JAMES, 2003).

$7 \quad$ Original: "The affair between Boston and Ted Williams has been no mere summer romance; it has been a marriage, composed of spats, mutual disappointments, and, toward the end, a mellowing hoard of shared memories. It falls into three stages, which may be termed Youth, Maturity, and Age; or Thesis, Antithesis, and Synthesis; or Jason, Achilles, and Nestor".

8 Original: "At the end of the inning, Higgins sent Williams out to his left-field position, then instantly replaced him with Carrol Hardy, so we had a long last look at Williams as he ran out there and then back, his uniform jogging, his eyes steadfast on the ground" 
Tanto o destinatário quanto o oponente se assemelham em uma ideia central. Os jornalistas, que atrapalharam a carreira do jogador de Boston quando ele ainda jogava profissionalmente, desejavam que ele desistisse, que está localizado no destinatário, na posteridade. Essa ideia pode ser representada pelo trecho: "No rádio do carro, enquanto eu dirigia para casa, eu ouvi que Williams tinha decidido não acompanhar o time para Nova Iorque. Então ele sabia como fazer até isso, a coisa mais difícil. Desistir"” (UPDIKE, 1960 apud DAWIDOFF, 2002, p. 317, tradução nossa).

A escolha da palavra inglesa "quit" se configura como uma das partes ficcionais da crônica, de acordo com os conceitos abordados na metodologia. Por que John Updike utiliza um termo de sentido mais próximo de desistir, abandonar, do que aposentar, como a expressão "retired", como habitualmente é usado nessa circunstância?

O "quit", intencional ou não, deixa no final da crônica uma sensação de fracasso, um encerramento dramático. E, se levarmos em consideração o título do texto, Hub Fans Bid Kid Adieu, o "adeus" corrobora com uma despedida trágica. Sendo assim, a narrativa criada por Updike se aproxima de uma elegia, uma poesia composta para funerais ou para lamentar a morte de alguém, comparando o fim da carreira de Ted Williams com um falecimento simbólico no esporte.

Mas Ted Williams, apesar de todas as polêmicas, não foi um fracasso. Assim como demonstrando em partes da crônica de Updike, Williams também conseguiu por duas vezes a Tripla Coroa $^{10}$ do esporte como rebatedor. Até hoje, o ex-jogador do Boston Red Sox é quem mais possui essa premiação, empatado com o jogador do Saint Louis Cardinals, Rogers Hornsby, ambos com duas (BASEBALL ALMANAC, 2015).

Além disso, Williams foi escolhido pelos jornalistas para o Hall da Fama em 1966, em sua primeira vez como elegível (JAMES, 2003). Se Williams tinha um mau relacionamento com os repórteres naquela época, como foi selecionado para o Hall da Fama logo na primeira tentativa? A informação é conflitante com as passagens da crônica que evidenciava os jornalistas como oponentes do jogador dos Red Sox.

Por fim, apesar de a crônica relatar a história do último dia de Williams no bastão, Updike se apresenta no texto, faz considerações e expõe o que

$9 \quad$ Original: "On the car radio as I drove home I heard that Williams had decided not to accompany the team to New York. So he knew how to do even that, the hardest thing. Quit".

10 A Tripla Coroa (Triple Crown, no original em inglês) é uma premiação ao rebatedor que liderar a Liga, Nacional ou Americana, em três estatísticas diferentes: home runs, média de rebatidas e corridas impulsionadas (BASEBALL ALMANAC, 2015). 
pensa, como na escolha da palavra “quit", diferente de Gay Talese (2004), por exemplo.

\begin{abstract}
Mas se permitíssemos que ele tivesse médias regulares de uma temporada nas quatro temporadas adicionais que ele perdeu durante a guerra, e adicionar uma outra temporada para os meses que ele perdeu machucado, teríamos um homem que em todos os totais de força seria o segundo, e um segundo não muito distante de Ruth ${ }^{11}$ (UPDIKE, 1960 apud DAWIDOFF, 2002, p. 317, tradução nossa).
\end{abstract}

John Updike, a partir de suposições e teorias, demonstrando toda a imprecisão e subjetividade do autor, coloca Williams como o segundo melhor jogador de beisebol da história. Assim como apresentado na crônica Shine Ball, Updike romantiza a despedida do ex-atleta do Boston e o compara "como uma pena pega por um vórtice"12 (UPDIKE, 1960 apud DAWIDOFF, 2002, p. 316, tradução nossa) ao relatar a corrida dele no bome run.

A corrida feita por Williams é a realidade, mas a inferência utilizada por Updike demonstra a subjetividade, a opinião dele sobre o lance, que é a verossimilhança, a ficção, já que não é possível conferir fidedignidade ao real quando ele compara o jogador dos Red Sox com uma pena em um vórtice, de tão leve e rápido que andava pelas bases.

\title{
Considerações finais
}

Em Hub Fans Bid Kid Adieu, John Updike prefere se inserir na narrativa: relatando, em primeira pessoa, a despedida de Ted Williams e relembrando algumas histórias do autor quando era mais jovem. Updike, então, mesmo escrevendo sobre essa despedida e não sendo o sujeito principal, apresenta ao leitor opiniões e inferências sobre o jogador dos Red Sox. Além disso, John Updike se posiciona e se utiliza de elementos literários e poéticos para caracterizar Ted Williams, demonstrando a subjetividade em seus textos.

A subjetividade é recorrente nas crônicas de beisebol do novo jornalismo. Se os discursos do novo jornalismo fossem baseados apenas na verdade considerada empírica, o real, na objetividade pura, não poderia existir a subjetiva, já que onde há vestígios de subjetividade partindo dos autores, há traços de ficcionalidade, assim como os dois mundos descritos pela Rosana

11 Original: "But if we allow him merely average seasons for the four-plus seasons he lost to two wars, and add another season for the months he lost to injuries, we get a man who in all the power totals would be second, and not a very distant second, to Ruth".

12 Original: "Like a feather caught in a vortex". 
Soares.

Os dois mundos não se excluem, não são contraditórios. As análises, com características marcantes do new journalism, representam verdades, a realidade, mas também contém ficcionalidade. Sempre ressaltado que essa ficção é diferente de fabulação, do absurdo. Mesmo no discurso considerado objetivo, a verdade não é totalmente pura, há traços da visão aproximada de Sartre, já que o autor retira da realidade sua concepção e a coloca em sua imaginação, criando um objeto irreal. Assim, é desta forma que a ficção e a realidade estão presentes nas crônicas de beisebol do novo jornalismo, se entrelaçando.

O conceito de Narratologia e o modelo atuacional greimasiano auxiliaram na fragmentação das crônicas, possibilitando analisar os atuantes e suas funções na narrativa, esmiuçando cada parte da narrativa. Assim, com as concepções de ficção e realidade dos autores Rosana Soares, Marcelo Bulhões e Jean-Paul Sartre também, foi possível identificar os elementos ficcionais e reais nos textos selecionados do new journalism de maneira mais aprofundada.

Apesar dos resultados apresentados, há outros elementos que não compunham a análise desta pesquisa. Por essa razão, sugerimos para trabalhos futuros um estudo que discuta e aprofunde a relação do new journalism com o jornalismo de revista norte-americano, já que as revistas, como The New Yorker e Esquire, são consideradas uma das primeiras a popularizar o novo estilo jornalístico. 
Sugerimos, também, um questionamento se o jornalista apaixonado pelo beisebol e torcedor pode ter contribuído para o jornalismo literário nos Estados Unidos, pois, antes mesmo do novo jornalismo, o beisebol já possuía características literárias.

Por fim, com a pesquisa, podemos ressaltar que existe ficção, enquanto subjetividade, nas crônicas de beisebol no novo jornalismo e, desta forma, demonstrando como essa união ficcional com a realidade constrói a cultura literária desse esporte. 


\section{Referências}

BASEBALL ALMANAC. Triple Crown of Baseball. Disponível em $<$ http://www.baseball-almanac.com/awards/aw_triph.shtml>. Acesso em 30 out. 2015.

BULHÕES, Marcelo. Jornalismo e Literatura em Convergência. São Paulo: Ática, 2007.

DAWIDOFF, Nicholas. Baseball: A literary Anthology. New York: The Library Of America, 2002.

GIL, Antonio Carlos. Métodos e Técnicas de Pesquisa Social. 6. ed. São Paulo: Atlas, 2014.

GREIMAS, Algirdas Julius. Semântica Estrutural: Pesquisa de Método. Tradução de: Haquira Osakabe e Izidoro Blikstein. São Paulo: Cultrix, 1973.

\section{IRVING, Washington. Knickerbocker's History of New York,} Complete. New York: Echo Library, 2007.

JAMES, Bill. The New Bill James Historical Baseball Abstract: The Classic. New York: Free Press, 2003.

LÈVI-STRAUSS, Claude. Antropologia Estrutural. Rio de Janeiro: Tempo Brasileiro, 1967.

PEÑUELA CAÑIZAL, Eduardo. Manifestação de recursos poéticos em dois filmes do Cinema Novo. Rumores, São Paulo, v. 1, n. 1, p.1-18, jul. 2007. Semestral. Disponível em < http://www.revistas.usp.br/Rumores/article/view/51091> Acesso em 04 jul. 2015.

PIDD, Helen. John Updike dies. The Guardian. 27 jan. 2009. Books. Disponível em <http://www.theguardian.com/books/2009/jan/27/author-john-updike-dies-at-76>. Acesso em 04 jul. 2015.

RECTOR, Monica. Para ler Greimas. Rio de Janeiro: Francisco Alves, 1978.

RIELLY, Edward. Baseball: An Encyclopedia of Popular Culture. Lincoln: University Of Nebraska Press, 2005.

SARTRE, Jean-Paul. O Imaginário: Psicologia fenomenológica da imaginação. São Paulo: Ática, 1996.

SOARES, Rosana de Lima. Pequeno inventário de narrativas midiáticas: verdade e ficção em discursos audiovisuais. Significação. São Paulo, v. 37, n. 34, p.55-72, jul. 2010. Disponível em <http://www.revistas.usp.br/signi- 
ficacao/article/view/68122>. Acesso em 04 jul. 2015.

TALESE, Gay. Fama e anonimato. Tradução de: Luciano Vieira Machado. $2^{a}$ ed. São Paulo: Companhia das Letras, 2004.

TELLES, Sérgio. Realismo a serviço da subjetividade. 10 jul. 2010. São Paulo. Cultura. Disponível em <http://cultura.estadao.com.br/noticias/ geral,realismo-a-servico-da-subjetividade-imp-,579169>. Acesso em 04 jul. 2015.

THE NEW YORKER. A New Yorker Timeline. Disponível em $<$ http://www.newyorker.com/about/a-new-yorker-timeline>. Acesso em 30 out. 2015. (a)

THE NEW YORKER. John Updike. Disponível em < http:/ /www. newyorker.com/contributors/john-updike>. Acesso em 30 out. 2015. (b)

VAQUER, Gabriel. ESPN volta a transmitir liga de baseball e comemora audiência. 2015. Disponível em <http://natelinha.ne10.uol. com.br/noticias/2015/04/04/espn-volta-a-transmitir-liga-de-baseball-ecomemora-audiencia-87630.php>. Acesso em17 maio 2015.

VIEIRA, Silvia; FREITAS, Armando. O que é Beisebol, Softbol e Hóquei sobre Grama. Rio de Janeiro: Casa da Palavra, 2009.

VITÓRIA Pírrica: A história (real) por trás da expressão. A história (real) por trás da expressão. 2013. Disponível em <https://medium.com/ historia-antiga/vitoria-pirrica-b95a4f342c10\#.cbs2hyvzs>. Acesso em 30 out. 2015.

WEINGARTEN, Marc. A turma que não escrevia direito. Tradução de: Bruno Cassoti. Rio de Janeiro: Record, 2010.

WOLFE, Tom. Radical Chique e o Novo Jornalismo. Tradução de: José Rubens Siqueira. $2^{\text {a }}$ ed. São Paulo: Companhia das Letras, 2005. 